\title{
Initial experience with balloon dilatation of supravalvar aortic stenosis
}

\author{
José Luiz Balthazar Jacob, Wilson Miguel Cecim Coelho, Nilton Carlos Spínola \\ Machado, Sérgio Aloísio Coimbra Garzon
}

\begin{abstract}
Primary balloon dilatation of supravalvar aortic stenosis was attempted in three patients: a 20 year old woman, a seven month old boy, and a 12 year old girl. Balloon catheters (Mansfield) with diameters of $25 \mathrm{~mm}, 8 \mathrm{~mm}$, and $15 \mathrm{~mm}$ were used in the three patients respectively. The systolic pressure gradient across the aortic narrowing decreased considerably and the diameter of the constricted area increased significantly.

Balloon dilatation was feasible and provided good immediate results and sustained relief of supravalvar aortic stenosis in these three patients. However, a larger study is needed to establish the place of this procedure in treatment.
\end{abstract}

(Br Heart $\mathcal{F} 1993 ; 70: 476-478)$

Supravalvar aortic stenosis is the least common cause of obstruction of the left ventricle outflow tract. It is caused by narrowing of the ascending aorta just above the aortic sinuses. There are three anatomical types: (a) hourglass, $(b)$ hypoplastic and $(c)$ membranous.

The good results reported with balloon dilatation of valvar, ${ }^{12}$ subvalvar, ${ }^{3-5}$ and supravalvar aortic stenosis, ${ }^{6}$ prompted us to attempt balloon dilatation of supravalvar aortic stenosis in three patients.

Instituto de Moléstias cardiovasculares de

São José do Rio Preto, São Paulo, Brasil

J L B Jacob

W M C Coelho

N C S Machado

S A C Garzon

Correspondence to:

Dr José Luiz Balthazar

Jacob, Rua Castelo D'Agua

Jacob, Rua Castelo D'Agua,

Preto, São Paulo, Brasil.

Accepted for publication

21 July 1993

Systolic gradient and diameter of the constriction before and immediately after balloon dilatation

\begin{tabular}{|c|c|c|c|c|c|c|}
\hline \multirow[b]{2}{*}{ Patient } & \multicolumn{3}{|c|}{ Gradient $(\mathrm{mm} \mathrm{Hg})$} & \multicolumn{3}{|c|}{ Diameter (mm) } \\
\hline & Before & After & Decrease (\%) & Before & After & Increase (\%) \\
\hline $\begin{array}{l}1 \\
2 \\
3\end{array}$ & $\begin{array}{r}64 \\
65 \\
102\end{array}$ & $\begin{array}{l}27 \\
15 \\
40\end{array}$ & $\begin{array}{l}57.8 \\
76.9 \\
60.7\end{array}$ & $\begin{array}{l}13 \\
4 \cdot 5 \\
9\end{array}$ & $\begin{array}{c}18.5 \\
8 \cdot 0 \\
13\end{array}$ & $\begin{array}{l}42 \\
77 \\
45\end{array}$ \\
\hline
\end{tabular}

murmur and thrill in the aortic area with radiation to the suprasternal notch and carotid arteries.

The electrocardiogram showed left ventricular hypertrophy in patients 1 and 3 and right ventricular hypertrophy in patient 2 . There were no associated abnormalities in any of the three patients.

Supravalvar aortic stenosis was diagnosed by cross sectional echocardiography. The systolic pressure gradients measured by Doppler echocardiography were $78 \mathrm{~mm} \mathrm{Hg}, 72 \mathrm{~mm}$ $\mathrm{Hg}$, and $104 \mathrm{~mm} \mathrm{Hg}$ in patients 1,2 , and 3 respectively. The pressures in the pulmonary artery and right ventricle derived from the modified Bernoulli formula or by the flow in pulmonary artery (Graettinger formula) were normal in all patients.

Patients were sedated with diazepam or meperidine and cardiac catheterisation was performed through the percutaneous femoral artery approach in patients 1 and 3 and by femoral arteriotomy in patient 2 .

Pressures in left ventricle and aorta were recorded through a NIH angiographic catheter. An aortogram and left ventriculogram obtained in left anterior oblique view showed supravalvar narrowing. Though other angiographic views can be used to measure the aortic diameter we prefer this view because it shows the opacified ascending aorta, aortic isthmus, and the thoracic descending aorta at the same time. If the portion of the ascending aorta above the stenosis had a diameter similar to the aortic isthmus it was regarded as normal. We calculated the diameter of the normal ascending aorta using a magnification factor for correction.

A 0.038 inch flexible tip guide wire that was $260 \mathrm{~cm}$ long (Cook) was passed through a pigtail catheter and advanced into the left ventricle. The pigtail catheter was withdrawn and a balloon catheter (Mansfield) (diameter $25 \mathrm{~mm}$ in patient $1,8 \mathrm{~mm}$ in patient 2 , and $15 \mathrm{~mm}$ in patient 3) was inserted over the guide wire and positioned across the narrowing and inflated three or four times, without use of manometer for $10-15$ seconds.

To reduce the risk of aneurysm formation or rupture of the aortic wall we never used a balloon catheter with a diameter bigger than the diameter of the normal aorta. In patients 2 and 3 we used balloons that were $1 \mathrm{~mm}$ smaller than the aortic diameter. Because in 


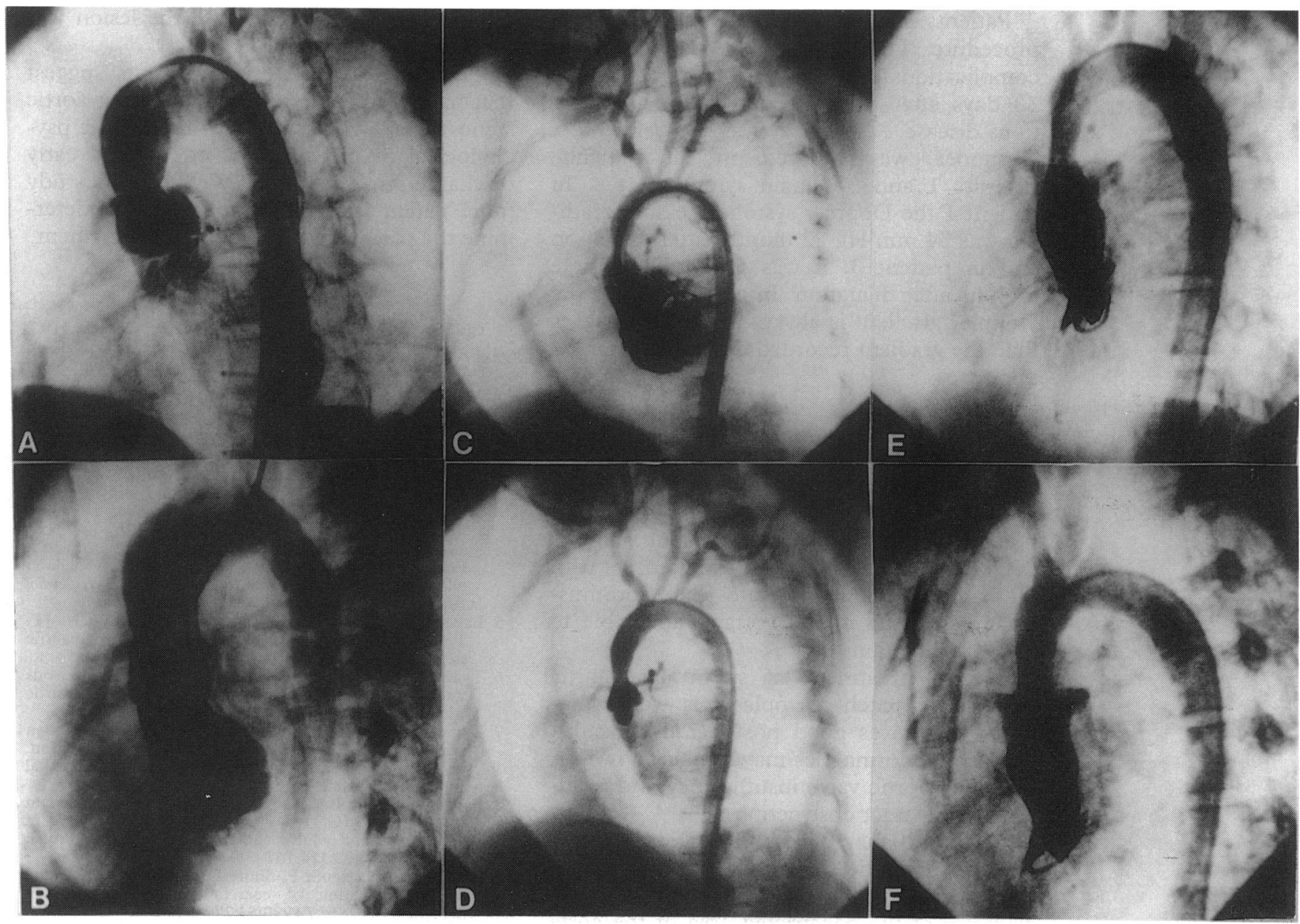

Figure 1 Aortic angiograms obtained before and after dilatation in patients 1 ( $A$ and $B)$, patient 2 (C and D), and patient $3(E$ and $F)$.

patient 1 the aorta above the stenosis was dilated we used a balloon with a diameter similar to the aortic annulus.

The guide wire was kept in position and the balloon catheter was replaced with the pigtail catheter. The guide wire was then removed and pressures in the left ventricle and aorta were recorded.

Repeat aortograms and left ventriculograms were obtained in left anterior oblique view.

\section{Results}

In all cases a systolic gradient was detected above the aortic valve. Mild (grade 1) aortic valve regurgitation was demonstrated angiographically in all the three patients before balloon dilatation. It did not increase after the procedure. All the three patients had hourglass aortic narrowing.

Left ventricular function was normal before and after the procedure in all patients. The table shows the gradient across the supravalvar stenosis and the diameter of the constricted segment before and after balloon dilatation.

Figures 1 and 2 show the angiographic images and the pressure recorded before and after balloon dilatation.
Figure 2 Aortic pressures recorded by withdrawal of the catheter through the aorta before and after dilatation in patient 1 ( $A$ and $B$ ), patient 2 ( $C$ and $D)$, and patient 3 ( $E$ and F). Numbers above the pressure curves are systolic aortic pressures in $\mathrm{mm} \mathrm{Hg}$.

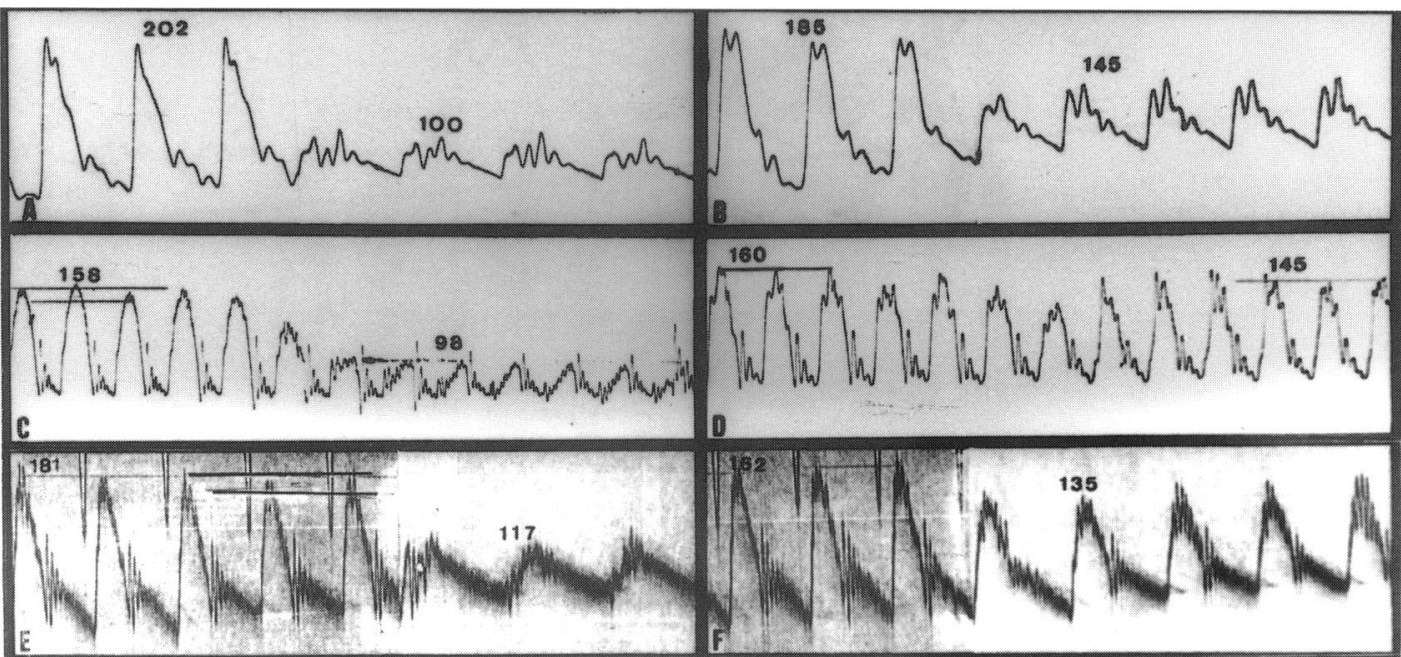


Patients were discharged 48 hours after the procedure. There were no procedure-related complications but the infant (patient 2) died 30 days after the procedure from an infectious disease. A necropsy was not performed. Dyspnoea was relieved in all patients. Patients 1 and 3 remain symptom free. In patient 1 the Doppler systolic pressure gradient was $34 \mathrm{~mm} \mathrm{Hg} 22$ months after dilatation and in patient 3 , it was $50 \mathrm{~mm} \mathrm{Hg}$ three months after dilatation. In our experience the Doppler gradient is always about $20 \%$ bigger than the gradient recorded during catheterisation.

\section{Discussion}

Balloon dilatation is a new and promising procedure for the treatment of aortic coarctation. $^{7-9}$ It has been used to treat stenosis caused by aortitis. ${ }^{10}$ Our experiences with these three patients indicates that fibromuscular narrowing of the aorta is amenable to balloon dilatation.

Surgical treatment of supravalvar aortic stenosis by patch aortoplasty is well established and gives good postoperative results. Residual abnormalities may remain, however, including aortic valve insufficiency and residual outflow tract obstruction. ${ }^{11}$

We found that balloon dilatation relieved supravalvar aortic stenosis. There was a considerable fall in the systolic gradient and the diameter of the constricted area of the aorta increased significantly.

Even in the patient who was 20 , the result was good and the late follow up showed sustained relief of stenosis. Dilatation was reported to be impossible in another 20 year old patient, probably because the lesion was rigid. ${ }^{6}$

The results in our three patients suggest that balloon dilatation of supravalvular aortic stenosis, gave good results with few little psychological or physical side effects and early discharge from hospital. We need to study more patients for longer follow up to determine the place of this procedure in treatment.

1 Choy M, Beekman RH, Rocchini AP, Crowley DC, Snider AR, Dick M, Rosenthal A. Percutaneous balloon valvuloplasty for valvar aortic stenosis in infants and children. Am 7 Cardiol 1987;59:1010-3.

2 Vogel M, Benson LN, Burrows P, Smallhorm JF, Freedom RM. Balloon dilatation of congenital aortic valve stenosis in infants and children: short term and valve stenosis in infants and children: short term
intermediate results. $\mathrm{Br}$ Heart $\mathcal{f} 1989 ; 62: 148-53$.

3 Suárez de Lezo J, Pan M, Medina A, Romero M, Melián $\mathrm{F}$, Seguro J, et al. Immediate and follow-up results of transluminal balloon dilation for discrete subaortic stenosis. F Am Coll Cardiol 1991;18:1309-15.

4 Suárez de Lezo J, Pan M, Sancho M, Herrera N, Arizon J, Franco $\mathrm{M}$, et al. Percutaneous transluminal balloon dilatation for discrete subaortic stenosis. $\mathrm{Am} \mathrm{f}$ Cardiol 1986;58:619-21.

5 Labadid Z, Weinhaush L, Stoeckle H, Walls JT. Transluminal balloon dilatation for discrete subaortic stenosis. Am $\mathcal{F}$ Cardiol 1987;59:423-5.

6 Tyagi S, Arora R, Kaul UA, Khalilullah M. Percutaneous transluminal balloon dilatation in supravalvular aortic stenosis. Am Heart $\mathcal{F}$ 1989;118:1041-4.

7 Tynan M, Finley JP, Fontes V, Hess J, Kan J. Balloon angioplasty for the treatment of native coarctation results of valvuloplasty and angioplasty of congenital anomalies registry. Am $₹$ Cardiol 1990;65:790-2.

8 Fauzi ME, Dunn B, Galal O, Wilson N, Shaikh A, Sriram $R$, Duran CMG. Balloon coarctation angioplasty in adolescents and adults: early and intermediate results. Am Heart $\mathcal{f} 1992 ; 124: 167-71$.

9 Redington AN, Booth P, Shore DF, Righy ML. Primary balloon dilatation of coarctation of the aorta in balloon dilatation of coarctation

10 Khalilullah M, Tyag S, Lochan R, Yadav BS, Nair M, Gambhir DS, Khanna SK. Percutaneous transluminal balloon angioplasty of the aorta in patients with aortitis. Circulation 1987;76:597-600.

11 Flaker G, Teske D, Kilman J, Hosier D, Wooley C. Supravalvular aortic Stenosis. A 20-year clinical perspective and experience with patch aortoplasty. $\mathrm{Am} \mathrm{f}$ Cardiol 1983;51:255-60. 